\title{
BMJ Open Design, methodology and baseline characteristics of Tai Chi and its protective effect against ischaemic stroke risk in an elderly community population with risk factors for ischaemic stroke: a randomised controlled trial
}

\author{
Guohua Zheng, ${ }^{1}$ Xin Zheng, ${ }^{1}$ Junzhe Li, ${ }^{1}$ Tingjin Duan, ${ }^{2}$ Dalu Qi, ${ }^{2}$ Kun Ling, ${ }^{2}$ \\ Jian $\mathrm{He},{ }^{1}$ Lidian Chen ${ }^{3}$
}

To cite: Zheng G, Zheng X, Li J, et al. Design, methodology and baseline characteristics of Tai Chi and its protective effect against ischaemic stroke risk in an elderly community population with risk factors for ischaemic stroke: a randomised controlled trial. BMJ Open 2015;5:e009158. doi:10.1136/bmjopen-2015009158

- Prepublication history for this paper is available online. To view these files please visit the journal online (http://dx.doi.org/10.1136/ bmjopen-2015-009158).

$\mathrm{JH}$ and LC are cocorresponding authors.

Received 25 June 2015 Revised 17 October 2015 Accepted 23 October 2015

\section{CrossMark}

For numbered affiliations see end of article.

Correspondence to Dr Jian He; 591003659@qq com and Professor Lidian Chen; lidianchen87@163.com

\section{ABSTRACT}

Introduction: Controlling risk factors with regular exercise is effective and cost-effective for the primary prevention of ischaemic stroke. As a traditional Chinese form of exercise, Tai Chi might be beneficial in decreasing ischaemic stroke, but the evidence remains insufficient. We hypothesise that elderly community adults with risk factors for ischaemic stroke will decrease their ischaemic stroke risk by improving cerebral haemodynamic parameters, cardiopulmonary function, motor function, plasma risk indices, physical parameters or psychological outcomes after receiving 12 weeks of regular Tai Chi training compared with those who maintained their original physical activities. Therefore, we designed a randomised controlled trial that will systematically evaluate the protective effects of Tai Chi exercise on ischaemic stroke risk in an elderly community population with risk factors for ischaemic stroke.

Methods and analysis: A total of 170 eligible participants were randomly allocated into either the Tai Chi training group or the usual physical activity group.

This paper reports on the design, intervention development and baseline characteristics of the participants. There were no significant differences between comparison groups in demographic characteristics or the baseline data of primary or secondary outcomes. Participants in the Tai Chi training group will receive 12 weeks of Tai Chi training with a frequency of 5 days/week and $60 \mathrm{~min} /$ day, while those in the usual physical activities group will maintain their original activities. Primary and secondary outcomes will be measured at the 12-week and 24-week follow-ups.

Ethics and dissemination: Ethical approval has been obtained from the Medical Ethics Committee of The Affiliated People's Hospital of Fujian University of Traditional Chinese Medicine (number 2013-020-02).

\section{Strengths and limitations of this study}

- This study will evaluate the protective effects of Tai Chi exercise on ischaemic stroke risk in an elderly community population with risk factors for ischaemic stroke.

- A prospective, randomised controlled study with blinded outcome measurements will be performed.

- Indirect and non-clinical end point measurements will be used to judge the protective effects of Tai Chi on ischaemic stroke risk.

- There have been insufficient samples and observation periods to investigate concrete outcomes (mortality, incidence of ischaemic stroke event).

The findings of this study will be communicated to healthcare professionals, participants and the public through peer-reviewed publications or scientific conferences.

Trial registration number: ChiCTR-TRC-13003601; Pre-results.

\section{INTRODUCTION}

Stroke is one of the most common causes of mortality and disability in adults worldwide, and it represents a large socioeconomic burden in most countries. ${ }^{1}{ }^{2}$ Globally, 15 million people suffer from an episode of stroke annually, and 5 million of these people are left permanently disabled. ${ }^{3}$ Despite mortality rates attributable to stroke gradually decreasing and having plateaued over the past 30 years in industrialised 
countries, due to the development of therapeutic strategies, the efficacy of primary or secondary prevention is often unsatisfactory. ${ }^{4}{ }^{5}$ Thus, the absolute numbers of cases of stroke and its disability burden will be dramatically increased over the next two decades with globally increasing life expectancy. ${ }^{6}$ Currently, therefore, stroke remains a large health burden worldwide.

The aetiology of stroke is multifactorial, and the key to stroke prevention is in the treatment of the major risk factors for stroke. Currently, more than 100 risk factors, which have been classified as non-modifiable, modifiable or potentially modifiable factors, have been identified as contributors to the pathogenetic progression of ischaemic stroke. ${ }^{78}$ Non-modifiable risk factors (eg, age, sex, ethnicity, low weight at birth, inherited diseases) usually serve as markers for high stroke risk, whereas modifiable risk factors, such as hypertension, diabetes mellitus, dyslipidaemia, waist-to-hip ratio, plasma inflammatory factors, dietary risk factors, asymptomatic cerebral or carotid stenosis and lack of physical activity, are amenable to intervention to decrease stroke risk. ${ }^{9}{ }^{10}$ Compelling results from clinical trials have indicated that control of risk factors markedly diminished the risk of stroke. ${ }^{11}{ }^{12}$ However, the optimal management of risk factors has remained limited.

Increasing evidence has shown that exercise is an effective intervention to prevent stroke and other cardiovascular and cerebrovascular diseases (CVDs). Exercise benefits include controlling the risk factors for stroke by decreasing obesity, hypertension, dyslipidaemia and the development of diabetes. ${ }^{13}{ }^{14}$ However, most of these health benefits occur with at least $150 \mathrm{~min} /$ week of moderate intensity, or $75 \mathrm{~min}$ /week of vigorous intensity of exercise. ${ }^{15}$ The prevalence of such exercise in the elderly is quite low; in addition, appropriate forms are scarce for elderly people because ageing is usually accompanied by a significant decline in organ function. ${ }^{16} 17$

Tai Chi, as a traditional Chinese mind-body exercise, has been practiced for several centuries in China and has also spread to Western countries over the past 20 years. It consists of a series of slow but continuous movements, which keep breathing and imagery in close cooperation. Through the combination of breathing and movements, the practitioner can achieve efficiency of 'body relaxation and mind calm'. ${ }^{18} 19$ Tai Chi is practiced in a semisquatting position, but the exercise intensity can be easily adjusted by controlling the speed and postural height; therefore, it is especially feasible for elderly people.

Tai Chi has been shown to have a variety of physical and psychological effects. For example, Tai Chi can help to improve body balance and physical fitness, ${ }^{20}$ and reduce depression and anxiety, ${ }^{21}$ and it is effective for fall prevention in elderly adults. ${ }^{22}$ As an accessible and cost-effective form of exercise, Tai Chi is increasingly popular for elderly people, and it might be an important intervention for the primary and secondary prevention of CVD. In fact, previous studies have demonstrated that regular Tai Chi training was effective in reducing blood pressure, ${ }^{23}$ preventing diabetes ${ }^{24}$ and improving dyslipidaemia, ${ }^{25}{ }^{26}$ which are determinants of stroke. Furthermore, several studies have shown Tai Chi to be helpful for aerobic capacity, ${ }^{27}$ cerebrovascular compliance and cardiorespiratory function, ${ }^{28}$ which are important because cardiac-cerebral vascular dysfunction is believed to a potential mechanism involved in the pathophysiological process of CVD. ${ }^{29}{ }^{30} \mathrm{~A}$ recent Cochrane systematic review suggested the probable beneficial effects of Tai Chi on CVD risk factors. ${ }^{31}$ Therefore, current evidence has concluded that Tai Chi is likely to protect against ischaemic stroke risk in the elderly community population, especially those people with risk factors for ischaemic stroke. As a result, we designed a randomised controlled trial of Tai Chi versus usual physical activity in the elderly community population with risk factors for ischaemic stroke. We hypothesise that individuals with high risk of ischaemic stroke who receive a 12-week Tai Chi exercise programme will have greater improvement in controlling risk factors for ischaemic stroke, and enhancing cerebrovascular and cardiopulmonary function, than those who maintain their usual physical activity as assessed immediately after the 12-week Tai Chi exercise intervention, and that these benefits will be sustained until the end of a 12-week follow-up. The aim is to demonstrate that, compared with usual physical activity, Tai Chi has protective effects against ischaemic stroke risk and is a suitable exercise for the elderly community population with risk factors for ischaemic stroke.

\section{MATERIALS AND METHODS}

\section{Study design}

This is a randomised, parallel, controlled trial to explore the effects of Tai Chi on ischaemic stroke risk in those in the elderly community with risk factors for ischaemic stroke by comparing a Tai Chi exercise intervention with usual physical activities. The elderly individuals who were randomly allocated to the Tai Chi group will undergo a 12-week Tai Chi exercise intervention with a frequency of $1 \mathrm{~h}$ /day for 5 days/week, based on their usual physical activities. The elderly people in the control group will not receive any specific exercise intervention (ie, they will maintain their usual, original physical activities habits). Primary or secondary outcomes will be measured at baseline, postintervention and after the follow-up period.

\section{Participants}

According to 'The 2012 Annual Screening and Intervention Project Workbook for the High Risk Stroke Population', the participants with a high risk of ischaemic stroke must meet two items from items $1-7$ and item 8: 
1. Current high blood pressure (systolic/diastolic pressure $\geq 140 / 90 \mathrm{~mm} \mathrm{Hg}$ ) or taking antihypertensive drugs;

2. Atrial fibrillation;

3. Currently smoking (at least one cigarette each day for 1 year);

4. Dyslipidaemia;

5. Diabetes mellitus;

6. Obvious overweight or obesity (body mass index (BMI) $\geq 24 \mathrm{~kg} / \mathrm{m}^{2}$ );

7. A family history of stroke (a stroke history in 3 generations);

8. A history of transient ischaemic attack.

To be eligible, the participant must meet the following criteria.

\section{Inclusion criteria}

1. Confirmed individuals with high risk or ischaemic stroke

2. No regular exercise for at least the past 1 year (regular exercise is defined as lasting more than 3 months with a frequency of $30 \mathrm{~min}$ or more, at least 1-3 times/week)

3. Male or female aged between 55 and 70 years

4. Informed consent.

\section{Exclusion criteria}

Participants who reported one of the following conditions were excluded:

1. History of stroke;

2. Suffering from severe CVDs, musculoskeletal system diseases or other sports contraindications;

3. Communication disorder.

\section{Recruitment}

Participants were recruited through community advertisements, posters and leaflets at a free clinic in a community centre in Gulou district, Fuzhou city. Two of the investigators contacted each individual who was interested in more information or who responded to the recruitment information. The investigators fully explained the study, including all of the potential benefits and risks. The participants were allowed to ask the investigators any questions prior to signing the informed consent statement. The investigator witnessed the informed consent statement after the participant signed and dated it. All of the participants provided informed consent prior to baseline measurements.

\section{Randomisation and concealment of allocation}

The eligible participants were randomly allocated to either the Tai Chi exercise group or the control group at a 1:1 ratio. A random allocation sequence was created using the PLAN procedure in SAS statistical software (V.9.1) by a statistician who was not involved in this trial at the Center for Evidence-based Chinese Medicine, Academy of Integrative Medicine, Fujian University of Traditional Chinese Medicine. Then, the allocation sequence was kept by a research assistant who was not involved in the recruitment, intervention, outcomes assessment or statistical analysis. After the participants met the study criteria and completed all of the baseline assessments, they were informed of their group allocation (either the Tai Chi or control group) by the research assistant, via telephone.

\section{Blinding}

Blinding of the participants and Tai Chi instructor was impossible in this study because they both knew the allocation result when Tai Chi training began. However, the outcome collectors and statistical analysts were blinded. Two types of blinding codes were kept by the research assistant. With the first blinding code, the allocation results were replaced by the letter $\mathrm{A}$ or $\mathrm{B}$, and the real meaning of the letter A or B was marked using the second blinding code. The research assistant will deliver letter $\mathrm{A}$ or $\mathrm{B}$ to the statistician after the database is closed and declare the real meaning of the letter A or B when all of the analysis of the data is completed.

\section{Intervention}

Tai Chi training

The 24 forms of simplified Tai Chi Chuan, which has been recommended as a popular, healthy sport by the Chinese National Sports Commission since $1956,{ }^{32}$ will be performed by the participants in the Tai Chi group. Participants will gather at a community centre and practice Tai Chi Chuan. The training regime of 5 sessions per week and 60 min per session for 12 weeks will be taught by certified instructors who have engaged in teaching Tai Chi Chuan for at least 5 years at Fujian University of Traditional Chinese Medicine. Sixty minutes of training time will include a $10 \mathrm{~min}$ warm up, $45 \mathrm{~min}$ practice and refinement, and a $5 \mathrm{~min}$ cool down. The 'meditation through movement' art of Tai Chi Chuan, including relaxation, breathing skills and coordinated movement of the arms, legs and body, as well as the philosophic opinions of Tai Chi Chuan, will be provided to the participants in the Tai Chi group. The 24 forms of simplified Tai Chi Chuan are shown in figure 1 .

\section{Usual physical activities}

The control group will maintain its original usual physical activities, which normally include housework, daily living activities, slow walking, shopping and babysitting, and they will not receive any regular exercise intervention during the 12-week intervention period.

\section{Study supervision}

The research assistant will record the daily attendance of the Tai Chi group and will investigate causes of absenteeism by telephone. The Tai Chi instructors will supervise participants' compliance in the Tai Chi group and correct the postures for Tai Chi movement during training. In addition, to analyse the impact of exceeding the 
usual physical activities, all of the participants in the Tai Chi group and the usual physical activities group, will be required to record their activity in logs, in which the duration and intensity of their activities for the whole day will be classified into three sections, including the durations of low-intensity activities, moderate-intensity activities and high-intensity activities.

\section{Follow-up}

After the 12-week intervention period, all of the participants will enter a 12-week unsupervised follow-up period, during which the participants in the Tai Chi group will return to their original lifestyles. All of the participants will be required to record their daily physical activity information on the physical activity form. The research assistant will go to each participant's home to collect these forms.

\section{Measurements}

Table 1 provides a brief summary of the types and schedules for the conduct of all of the assessments in the study. The primary outcomes consist of cerebral haemodynamic parameters. Secondary outcomes include cardiopulmonary function (resting pulmonary function, cardiac structure and function), plasma risk indicators of CVD (blood lipid, fasting blood glucose and homocysteine), motor capability (balance function, lumbar and lower limb proprioception function, 6 min walk test), physical parameters (body mass index, waist-to-hip ratio, sit-and-reach, one foot stand with eyes closed) and psychological outcomes (health-related quality of life, quality of sleep and mood). All of the measurements will be obtained by personnel blinded to participants' randomisation allocation.

\section{Primary outcome measurements}

Cerebral haemodynamic parameters will include maximum blood flow velocity $\left(\mathrm{V}_{\max }\right)$, minimum blood flow velocity $\left(\mathrm{V}_{\text {min }}\right)$, mean blood flow velocity $\left(\mathrm{V}_{\text {mean }}\right)$, pulsatility index (PI) and vascular resistance index (RI). The bilateral vertebral artery (VA), bilateral middle cerebral artery (MCA), bilateral anterior cerebral artery (ACA) and bilateral posterior cerebral artery (PCA) of the brain and the basilar artery (BA) will be measured using a colour Doppler ultrasound imaging device (Philips, product type: IU22) by the professional operators at Fujian University of Traditional Chinese Medicine Subsidiary Rehabilitation Hospital.
Figure 1 Specification of 24 forms of simplified Tai Chi Chuan.
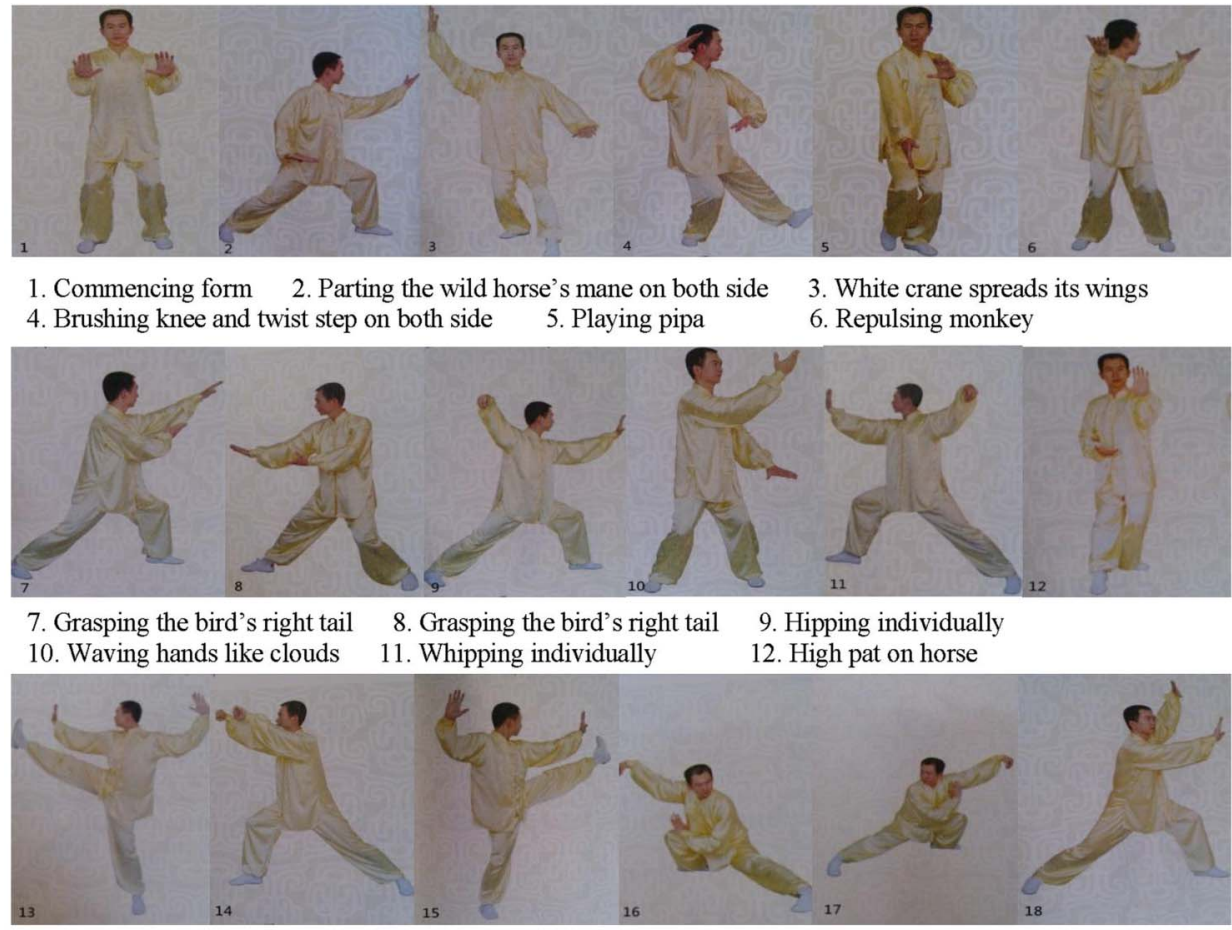

13. Kicking with right heel

14. Striking opponent's ears with both fists

15. Kicking with left heel 16. Snaking left creeps down 17. Snaking right creeps down

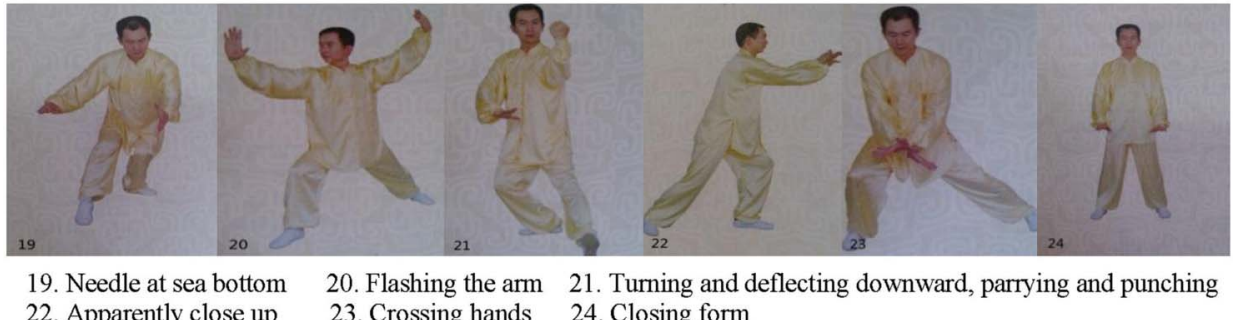

22. Apparently close up 23. Crossing hands 24. Closing form 
Table 1 Brief description of outcome assessments

\begin{tabular}{|c|c|c|c|}
\hline Items & $\begin{array}{l}\text { Recruitment } \\
-2-(-1) \text { weeks }\end{array}$ & $\begin{array}{l}\text { Post-training } \\
\text { 12-week }\end{array}$ & $\begin{array}{l}\text { Post follow-up } \\
\text { 24-week }\end{array}$ \\
\hline Demographic characteristics & $x$ & & \\
\hline Cerebral haemodynamic parameters & $x$ & $x$ & $x$ \\
\hline \multicolumn{4}{|l|}{ Cardiopulmonary function } \\
\hline Cardiac structure and function & $x$ & $x$ & $x$ \\
\hline Resting pulmonary function & $x$ & $x$ & $x$ \\
\hline \multicolumn{4}{|l|}{ Plasma risk indicators of cardiovascular disease } \\
\hline Blood lipid & $x$ & $x$ & $x$ \\
\hline Fasting blood glucose & $x$ & $x$ & $x$ \\
\hline Homocysteine & $x$ & $x$ & $x$ \\
\hline \multicolumn{4}{|l|}{ Motor capability } \\
\hline Balance function & $x$ & $x$ & $x$ \\
\hline Lower limbs proprioception function & $x$ & $x$ & $x$ \\
\hline \multicolumn{4}{|l|}{ Physical parameters } \\
\hline Body mass index & $x$ & $x$ & $x$ \\
\hline Waist-to-hip ratio & $x$ & $x$ & $x$ \\
\hline 6 min walk test & $x$ & $x$ & $x$ \\
\hline Sit-and-reach & $x$ & $x$ & $x$ \\
\hline Time for one foot standing with eyes closed & $x$ & $x$ & $x$ \\
\hline \multicolumn{4}{|l|}{ Psychological outcomes } \\
\hline Health-related quality of life & $x$ & $x$ & $x$ \\
\hline Quality of sleep & $x$ & $x$ & $x$ \\
\hline Mood & $x$ & $x$ & $x$ \\
\hline Safety assessments & & $x$ & \\
\hline
\end{tabular}

\section{Secondary outcome measurements}

- Cardiopulmonary function: Including cardiac structure, and function and static lung function.

- Cardiac structure and function: Cardiac structure and function including aortic diameter, left atrial diameter, interventricular septum thickness, left ventricular diastolic diameter, left ventricular posterior wall thickness, left ventricular anterior wall thickness, right atrial diameter, right ventricle diameter, main pulmonary artery diameter and left ventricular fraction, will be measured using a colour Doppler ultrasound imaging device (product type: Siemans Acuson X300) by the professional operators at the Health Check Center of the Second People's Hospital of Fujian Province.

- Static lung function: Static lung function includes vital capacity MAX (VC MAX), forced expiratory volume in $1 \mathrm{~s}$ (FEV1), FEV1\%FVC (forced vital capacity), and maximal voluntary ventilation (MVV), which will be measured using a cardiopulmonary function instrument (Jaeger, Germany, product type: OXYCON PRO PC) by the professional operators at Fujian University of Traditional Chinese Medicine Subsidiary Rehabilitation Hospital.

- Plasma risk factor indicators: Plasma risk factor indicators include total cholesterol (TC), triglyceride (TG), low-density lipoprotein (LDL) and high-density lipoprotein (HDL), fasting blood glucose (FBG) and homocysteine (HCY). Blood profiles will be measured according to the specifications of the fasting period.
Blood samples will be collected at Fujian University of Traditional Chinese Medicine Subsidiary Rehabilitation Hospital. Standardised measurements of TC, TG, FBG and HCY will be performed using the enzymatic method. The clearance method will be applied to measure plasma LDL levels; in addition, plasma HDL levels will also be measured by the inhibition method.

- Motor capability: The motor capability involved in balance and proprioception function will be measured using Prokin systems (product type: PK254P), produced by Italy Tecnobody Srl, at Fujian University of Traditional Chinese Medicine Subsidiary Rehabilitation Hospital.

- Physical parameters: Physical parameters consist of BMI, waist-to-hip ratio (WHR), flexibility, 6 min walk test (6MWD) and time on one foot standing with eyes closed. BMI will be assessed using a body scale. Waist-to-hip ratio will be tested using a metric ruler. Flexibility will be measured with the 'sit and reach' test, using a 'sit and reach' tester produced by Zhongtitongfang Co, Ltd, Beijing (product type: CSTF-TQ-5000). All of the above measurements will be performed by the outcome assessors blinded to the participants' randomisation assignments.

- Psychological outcomes: Psychological outcomes include health-related quality of life, quality of sleep and mood.

- Health-related quality of life: Health-related quality of life will be assessed using the Chinese version of the 
SF-36 scale. ${ }^{33}$ This scale consists of 36 items to assess eight health concepts: Physical Functioning (PF) (10 items), Role Physical (RP) (4 items), Bodily Pain (BP) (2 items), General Health (GH) (5 items), Vitality (VT) (4 items), Social Functioning (SF) (2 items), Role Emotional (RE) (3 items) and Mental Health (MH) (5 items). ${ }^{34}$ The Chinese version of the SF-36 has been reported to be reliable, including split-half reliability, internal consistency, criterion validity and structure validity, by Jin and $\mathrm{Yu}^{35}$

- Quality of sleep: Quality of sleep will be evaluated using the Pittsburgh Sleep Quality Index (PSQI), which is a self-rated questionnaire to assess sleep quality within 1 month. ${ }^{36}$ Nineteen items generate seven dimensions: subjective sleep quality, sleep latency, sleep duration, habitual sleep efficiency, sleep disturbances, use of sleeping medication and daytime dysfunction. ${ }^{37}$ Acceptable internal consistency, construct validity, criterion-related validity and the test-retest reliability of the Chinese version of the PSQI have been demonstrated. ${ }^{38} 39$

- Mood: Mood will be assessed by the Profile of Mood States Short Form (POMS-SF), which was proven to be an excellent measure of affective mood state fluctuation in a wide variety of populations with stronger reliability and validity. ${ }^{40}$ The Chinese version of the BPOMS has been reported to have acceptable internal consistency, construct validity and criterion-related validity, by Song and Wen. ${ }^{41}$

\section{Safety assessments}

Any expected or unexpected adverse events related to the Tai Chi intervention will be reported to research assistants and recorded on case report forms. All adverse events will be analysed for causality due to the Tai Chi intervention. Serious adverse events will be reported to the primary researchers and ethics committee. The primary researchers and ethics committee will assess their severity and make a decision regarding whether the participant needs to withdraw from this study.

\section{Data management}

The data are collected through the print-based case report forms ( $p$-CRFs) written by the outcomes assessors and entered into Web-based case report forms (w-CRFs) at electronic data capture (EDC) systems by research assistants. The integrity of data will be enforced when the data are entered into w-CRFs by means of checks on value ranges and logical checks. The EDC system and Web servers are hosted in the centre for data management of FJTCM, and they meet the available standards for security (http://210.34.74.191/srtp/users/ loginlangth.action). The participants' data from w-CRFs will be stored in the EDC system in separate passwordprotected locations.

Access to and exporting of w-CRFs data are limited to those data management staff working in the centre for data management who are not involved in the conduct of the trial. Final data cleaning, data locking and data analysis will be performed at the centre for data management. All data management will be undertaken without access to the randomisation allocation sequence.

\section{Sample size calculation}

The sample size was calculated using the data from a reference that investigated cerebral haemodynamic parameters among people in the elderly community who have ischaemic stroke risk, using a colour Doppler ultrasound imaging device. ${ }^{42}$ Owing to the lack of availability of previous studies focusing on Tai Chi exercise for cerebral haemodynamic parameters, we anticipate an average of $10 \%$ improvement in cerebral haemodynamic parameters among participants undergoing the 12-week Tai Chi training compared with those participants performing their usual physical activities, based on the consideration of clinical significance. According to data on cerebral haemodynamic parameters in the reference, ${ }^{34}$ the maximum sample size of 74 in each group was required for $80 \%$ power and two-sided significance $\alpha$ level of 0.05 to detect a difference of $3.2 \mathrm{~mL} / \mathrm{min}$ in average blood flow velocity of the $\mathrm{BA}$ and to assume an $\mathrm{SD}$ of $6 \mathrm{~mL} / \mathrm{min}$ (a mean of $32 \mathrm{~mL} / \mathrm{min}$ and SD of $6 \mathrm{~mL} / \mathrm{min}$ in average blood flow velocity of the BA was reported in another reference ${ }^{42}$ ). In anticipation of a $15 \%$ dropout rate, the optimal simple size would be 85 per group.

\section{Statistical analysis}

The continuous variables will be expressed using means with SDs or medians with interquartile ranges for nonnormal distributions. The categorical variables will be expressed as appropriate. Statistical comparisons between the groups in baseline characteristics were analysed using the $\mathrm{t}$ test or the Mann-Whitney test for

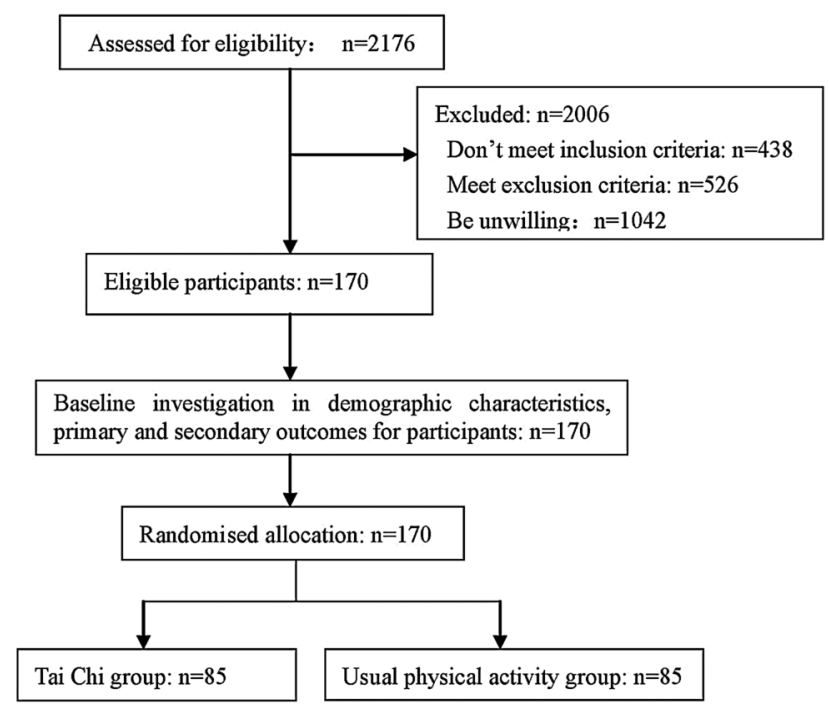

Figure 2 Flow chart of participants' recruitment and trial design. 
Table 2 Baseline demographic characteristics of participants between Tai Chi group and control group

\begin{tabular}{|c|c|c|c|c|}
\hline Variable & $\begin{array}{l}\text { Tai Chi group } \\
(n=85)\end{array}$ & $\begin{array}{l}\text { Usual physical } \\
\text { activity group } \\
(n=85)\end{array}$ & T value $\left(\chi^{2}\right)$ & p Value \\
\hline Age, years $($ mean $\pm S D)$ & $61.01 \pm 5.20$ & $60.73 \pm 6.05$ & 0.326 & 0.744 \\
\hline Seated systolic BP, $\mathrm{mm} \mathrm{Hg}($ mean $\pm S D)$ & $133.81 \pm 16.74$ & $129.04 \pm 15.94$ & 1.906 & 0.058 \\
\hline Seated diastolic BP, $\mathrm{mm} \mathrm{Hg}($ mean $\pm \mathrm{SD})$ & $77.74 \pm 9.28$ & $76.35 \pm 10.48$ & 0.914 & 0.362 \\
\hline Height, cm (mean $\pm S D)$ & $160.41 \pm 7.42$ & $159.70 \pm 7.46$ & 0.622 & 0.534 \\
\hline Body weight, $\mathrm{kg}$ (mean $\pm \mathrm{SD})$ & $65.312 \pm 9.53$ & $64.14 \pm 10.90$ & 0.744 & 0.458 \\
\hline Average daily activity time, $\mathrm{h}$ (median, $25-75 \%$ ) & $4.429(6.964-2.071)$ & $4.857(6.892-2.857)$ & -0.577 & 0.564 \\
\hline \multicolumn{5}{|l|}{ Gender (n, \%) } \\
\hline Male & $28(32.9)$ & $24(28.2)$ & 0.443 & 0.506 \\
\hline Female & $57(67.1)$ & $61(71.8)$ & & \\
\hline \multicolumn{5}{|l|}{ Nationality (n, \%) } \\
\hline Han nationality & $84(99.8)$ & $85(100)$ & 1.006 & 0.316 \\
\hline Minority nationality & $1(0.2)$ & $0(0)$ & & \\
\hline \multicolumn{5}{|l|}{ Marital (n, \%) } \\
\hline Married & 79 (92.9) & $80(94.1)$ & 1.406 & 0.495 \\
\hline Widowed & $6(7.1)$ & $4(4.7)$ & & \\
\hline Divorced & $0(0)$ & $1(1.2)$ & & \\
\hline \multicolumn{5}{|l|}{ Lever of education (n, \%) } \\
\hline Primary school & $11(12.9)$ & $19(22.4)$ & 7.681 & 0.053 \\
\hline Junior high school & $33(38.8)$ & $18(21.2)$ & & \\
\hline Senior high school & $25(29.5)$ & $33(38.8)$ & & \\
\hline High school or above & $16(18.8)$ & $15(17.6)$ & & \\
\hline \multicolumn{5}{|l|}{ History of heart disease (n, \%) } \\
\hline Yes & $9(10.6)$ & $14(16.5)$ & 1.257 & 0.262 \\
\hline No & $76(89.4)$ & $71(83.5)$ & & \\
\hline \multicolumn{5}{|l|}{ History of diabetes (n, \%) } \\
\hline Yes & $8(9.4)$ & $11(12.9)$ & 0.533 & 0.465 \\
\hline No & 77 (90.6) & $74(87.1)$ & & \\
\hline \multicolumn{5}{|l|}{ History of hypertension (n, \%) } \\
\hline Yes & 39 (45.9) & $38(44.7)$ & 0.024 & 0.878 \\
\hline No & $46(54.1)$ & $47(55.3)$ & & \\
\hline \multicolumn{5}{|l|}{ History of dyslipidaemia (n, \%) } \\
\hline Yes & $50(58.8)$ & $53(62.4)$ & 0.222 & 0.638 \\
\hline No & $35(41.2)$ & $32(37.6)$ & & \\
\hline \multicolumn{5}{|l|}{ Family history of stroke $(n, \%)$} \\
\hline Yes & $16(18.8)$ & $15(17.7)$ & 0.039 & 0.843 \\
\hline No & 69 (81.2) & 70 (82.3) & & \\
\hline \multicolumn{5}{|l|}{ Smoking (n, \%) } \\
\hline Yes & $11(12.9)$ & $15(17.7)$ & 0.726 & 0.394 \\
\hline No & $74(87.1)$ & 70 (82.3) & & \\
\hline \multicolumn{5}{|l|}{ Drinking (n, \%) } \\
\hline Yes & $23(27.1)$ & $28(32.9)$ & 0.700 & 0.403 \\
\hline No & $62(72.9)$ & $57(67.1)$ & & \\
\hline
\end{tabular}

continuous variables and Pearson's $\chi^{2}$ test or Fisher's exact test for categorical variables.

The primary analysis will compare the changes in cerebral haemodynamic parameters from baseline to the end point of the follow-up period between the comparison groups, using repeated analysis of variance (ANOVA) or analysis of covariance, adjusting by the cerebral haemodynamic parameter baseline values.

Secondary analyses will assess changes in secondary outcomes from baseline to the endpoint of the follow-up period between the Tai Chi group and the control group. All of the analyses will follow the template for the primary outcomes.

Primary and secondary analyses will be based on the intension-to-treat (ITT) principle, and the missing data will be imputed using the multiple imputation method. Subgroup analysis, stratified by characteristics of the risk factors for ischaemic stroke, will be used for the primary outcomes. Adverse events will be listed and analysed using the $\chi^{2}$ test or Fisher's exact test. All of the statistical tests will be performed using IBM SPSS (IBM Inc, Chicago, Illinois, USA) V.21.0 statistical software 
Table 3 Baseline cerebral haemodynamic parameters between Tai Chi group and usual physical activities group

\section{Tai Chi group}

\begin{tabular}{lll}
\cline { 3 - 3 } Variables & $\mathbf{n}$ & $\begin{array}{l}\text { Mean } \pm \text { SD } \\
\text { (Median, 25\%-75\%) }\end{array}$ \\
\hline Basilar artery & & \\
$\mathrm{V}_{\text {max }}, \mathrm{cm} / \mathrm{s}$ & 82 & $65.89 \pm 17.62$ \\
$\mathrm{~V}_{\text {min }}, \mathrm{cm} / \mathrm{s}$ & 82 & $59.34 \pm 16.55$ \\
$\mathrm{~V}_{\text {mean }}, \mathrm{cm} / \mathrm{s}$ & 82 & $62.57 \pm 16.75$ \\
$\mathrm{PI}$ & 82 & $0.92 \pm 0.19$ \\
$\mathrm{RI}$ & 82 & $0.57 \pm 0.07$ \\
Missing* & 3 & \\
Left vertebral artery & & \\
$\mathrm{V}_{\text {max }}, \mathrm{cm} / \mathrm{s}$ & 82 & $59.0(68.25-46.0)$ \\
$\mathrm{V}_{\text {min }}, \mathrm{cm} / \mathrm{s}$ & 82 & $52.0(59.75-40.0)$ \\
$\mathrm{V}_{\text {mean }}, \mathrm{cm} / \mathrm{s}$ & 82 & $56.0(63.50-43.0)$ \\
$\mathrm{PI}$ & 82 & $0.91 \pm 0.19$ \\
$\mathrm{RI}$ & 82 & $0.56 \pm 0.07$
\end{tabular}

Missing $^{*} \quad 3$

Right vertebral artery

$\begin{array}{ll}\mathrm{V}_{\text {max }}, \mathrm{cm} / \mathrm{s} & 82 \\ \mathrm{~V}_{\text {min }}, \mathrm{cm} / \mathrm{s} & 82 \\ \mathrm{~V}_{\text {mean }}, \mathrm{cm} / \mathrm{s} & 82 \\ \mathrm{PI} & 82 \\ \mathrm{RI} & 82 \\ \text { Missing } & 3\end{array}$

Left anterior cerebral artery

$\begin{array}{lll}\mathrm{V}_{\max }, \mathrm{cm} / \mathrm{s} & 60 & 80.57 \pm 20.17 \\ \mathrm{~V}_{\min }, \mathrm{cm} / \mathrm{s} & 60 & 71.5(81.75-60.0) \\ \mathrm{V}_{\text {mean }}, \mathrm{cm} / \mathrm{s} & 60 & 75.0(84.75-64.0) \\ \mathrm{PI} & 60 & 0.86 \pm 0.17 \\ \mathrm{RI} & 60 & 0.54 \pm 0.07 \\ \text { Missing } & 25 & \end{array}$

Missing 25

Right anterior cerebral artery

$\begin{array}{lll}\mathrm{V}_{\text {max }}, \mathrm{cm} / \mathrm{s} & 55 & 80.0(95.00-64 . \\ \mathrm{V}_{\text {min }}, \mathrm{cm} / \mathrm{s} & 55 & 73.49 \pm 20.53 \\ \mathrm{~V}_{\text {mean }}, \mathrm{cm} / \mathrm{s} & 55 & 77.38 \pm 21.00 \\ \mathrm{Pl} & 55 & 0.85 \pm 0.15 \\ \mathrm{RI} & 55 & 0.54 \pm 0.06 \\ \text { Missing } & 30 & \\ \text { eft middle cerebral artery } & \\ \mathrm{V}_{\text {max }}, \mathrm{cm} / \mathrm{s} & 60 & 93.27 \pm 21.59 \\ \mathrm{~V}_{\text {min }}, \mathrm{cm} / \mathrm{s} & 60 & 85.37 \pm 20.87 \\ \mathrm{~V}_{\text {mean }}, \mathrm{cm} / \mathrm{s} & 60 & 89.08 \pm 20.72 \\ \mathrm{PI} & 60 & 0.88 \pm 0.15 \\ \mathrm{RI} & 60 & 0.55 \pm 0.06\end{array}$

Missing 25

Right middle cerebral artery

$\begin{array}{lll}\mathrm{V}_{\max }, \mathrm{cm} / \mathrm{s} & 55 & 90.95 \pm 24.31 \\ \mathrm{~V}_{\min }, \mathrm{cm} / \mathrm{s} & 55 & 83.44 \pm 23.29 \\ \mathrm{~V}_{\text {mean }}, \mathrm{cm} / \mathrm{s} & 55 & 87.71 \pm 24.07 \\ \mathrm{PI} & 55 & 0.87 \pm 0.13 \\ \mathrm{RI} & 55 & 0.55 \pm 0.07 \\ \text { Missing } & 30 & \\ \text { eft posterior cerebral artery } & \\ \mathrm{V}_{\max }, \mathrm{cm} / \mathrm{s} & 61 & 51.26 \pm 9.87 \\ \mathrm{~V}_{\min }, \mathrm{cm} / \mathrm{s} & 61 & 46.26 \pm 9.01 \\ \mathrm{~V}_{\operatorname{mean}}, \mathrm{cm} / \mathrm{s} & 61 & 49.00 \pm 9.41 \\ \mathrm{PI} & 61 & 0.91 \pm 0.15 \\ \mathrm{RI} & 61 & 0.56 \pm 0.06 \\ \text { Missing } & 24 & \end{array}$

\section{Usual physical activity}

group

$\begin{array}{lll}59.32 \pm 16.95 & 82 & 58.13 \pm 16.12 \\ 52.37 \pm 15.51 & 82 & 51.06 \pm 14.65 \\ 55.73 \pm 16.12 & 82 & 54.72 \pm 15.26 \\ 0.93 \pm 0.20 & 82 & 0.97 \pm 0.19 \\ 0.57 \pm 0.07 & 82 & 0.58 \pm 0.07\end{array}$

$56.0(69.0-45.5)$

$49.0(60.0-39.0)$

$52.0(66.0-41.5)$

$0.94 \pm 0.21$

$0.57 \pm 0.08$

$62.84 \pm 16.57$

$56.71 \pm 15.42$
$59.91+15.98$

$0.95 \pm 0.25$

$0.58 \pm 0.09$

69

69

69

69

69

16

$82.78 \pm 18.73$

76.00 (89.00-58.50)

78.00 (92.50-64.50)

$0.90 \pm 0.20$

$0.56 \pm 0.08$

77.0 (94.0-68.0)

$72.44 \pm 19.66$

$76.04 \pm 19.53$

$0.90 \pm 0.20$

$0.56 \pm 0.08$

30

$71 \quad 94.65 \pm 21.65$

$71 \quad 87.58 \pm 21.00$

$90.72 \pm 21.26$

$0.92 \pm 0.19$

$0.57 \pm 0.07$

14

63

$96.38 \pm 21.15$

$87.79 \pm 20.75$

$91.79 \pm 21.03$

$0.88 \pm 0.16$

$0.55 \pm 0.06$

$53.31 \pm 11.92$

$47.21 \pm 11.13$

$50.12 \pm 11.46$

$0.93 \pm 0.19$

$0.57 \pm 0.07$
$\mathrm{T}$ value $/ \mathbf{Z}$

value $\chi^{2}$ value $\quad p$ Value

1.155

1.065

1.053

$-0.902$

$-0.593$

$-0.463$

$-0.608$

$-0.453$

$-1.223$

$-1.291$

0.250

0.288

0.294

0.368

0.554

0.246

0.644

0.543

0.650

0.223

0.198

0.246

0.458

0.554

0.413

$-1.346$

$-1.348$

0

0.648

0.580

0.680

0.180

0.180

1.0

$-0.647$

1.037

$-1.013$

$-1.397$

$-1.283$

2.604

$-0.006$

0.275

0.348

$-1.472$

$-1.859$

0

0.519

0.300

0.311

0.165

0.202

0.107

0.995

0.784

0.729

0.144

0.066

1.0

$-0.364$

$-0.603$

$-0.444$

$-1.199$

$-1.199$

4.026

0.716

0.548

0.658

0.233

0.265

0.045

$-1.299$

0.197

$-1.075$

0.285

$-0.984$

0.327

0.628

0.797

$-0.257$

0.183

1.773

0.387

$-0.869$

$-0.525$

$-0.601$

0.600

0.549

$-0.622$

0.535

$-0.558$

1.575 
Table 3 Continued

\begin{tabular}{|c|c|c|c|c|c|c|}
\hline \multirow[b]{2}{*}{ Variables } & \multicolumn{2}{|c|}{ Tai Chi group } & \multicolumn{2}{|c|}{$\begin{array}{l}\text { Usual physical activity } \\
\text { group }\end{array}$} & \multirow[b]{2}{*}{$\begin{array}{l}\text { T value } / Z \\
\text { value } / \chi^{2} \text { value }\end{array}$} & \multirow[b]{2}{*}{ p Value } \\
\hline & $\mathbf{n}$ & $\begin{array}{l}\text { Mean } \pm \text { SD } \\
\text { (Median, 25\%-75\%) }\end{array}$ & $\mathbf{n}$ & $\begin{array}{l}\text { Mean } \pm \text { SD } \\
\text { (Median, 25\%-75\%) }\end{array}$ & & \\
\hline \multicolumn{7}{|c|}{ Right posterior cerebral artery } \\
\hline $\mathrm{V}_{\max }, \mathrm{cm} / \mathrm{s}$ & 57 & $51.07 \pm 11.21$ & 54 & $50.89 \pm 10.73$ & 0.087 & 0.931 \\
\hline $\mathrm{V}_{\min }, \mathrm{cm} / \mathrm{s}$ & 57 & $44.46 \pm 9.80$ & 54 & $44.87 \pm 9.43$ & -0.227 & 0.821 \\
\hline $\mathrm{V}_{\text {mean }}, \mathrm{cm} / \mathrm{s}$ & 57 & $47.72 \pm 10.27$ & 54 & $48.15 \pm 10.20$ & -0.221 & 0.826 \\
\hline $\mathrm{Pl}$ & 57 & $0.88 \pm 0.16$ & 54 & $0.92 \pm 0.17$ & -1.117 & 0.267 \\
\hline $\mathrm{RI}$ & 57 & $0.55 \pm 0.06$ & 54 & $0.56 \pm 0.07$ & -1.010 & 0.315 \\
\hline Missing & 28 & & 31 & & 0.234 & 0.629 \\
\hline
\end{tabular}

Missing*, Fisher's exact test; Missing, Pearson's $\chi^{2}$ test; PI, pulsatility index; RI, resistance index; $\mathrm{V}_{\max }$, maximum blood flow velocity; $\mathrm{V}_{\text {mean }}$, mean blood flow velocity; $V_{\min }$, minimum blood flow velocity.

packages. Statistical significance will be defined as a twosided $p$ value of $\leq 0.05$.

\section{Ethics and dissemination}

All of the participants provided written informed consent before being enrolled.

The study will be conducted according to the Declaration of Helsinki. The findings of this study will be communicated to healthcare professionals, the participants and the public through peer-reviewed publications or scientific conferences.

\section{Baseline results}

Recruitment began in October 2014 and was completed in March 2015. A total of 2176 individuals were screened for eligibility: 438 participants did not meet the inclusion criteria, 526 were excluded due to the exclusion criteria and 1042 were unwilling to participate in the study. Finally, a total of 170 eligible participants were randomised into the study. The flow of the participants through the recruitment process and randomisation is shown in figure 2.

Table 2 lists the baseline characteristics collected at recruitment from the 170 participants. As shown, the randomisation of the two groups of participants with high risk of ischaemic stroke with similar characteristics had no differences in baseline demographic characteristics, including age, blood pressure, height, body weight, average daily moderate activity time, sex, nationality, marital status or level of education. In addition, no differences in history of diseases, family history of stroke, drinking or smoking were noted.

Tables 3 and 4 display the baseline data of the primary and secondary outcomes of the study samples. No differences between the Tai Chi and control groups were observed in cerebral haemodynamic parameters, cardiac structure and function, static lung function, plasma risk factors, balance and proprioception capability, physical parameters, Pittsburgh sleep quality index or Profile of Mood States Short Form, but SF-36 Physical component and Mental component summary scores in the Tai Chi group were slightly higher than those in the control group. Overall, the randomisation process established two groups of participants with similar baseline characteristics.

\section{DISCUSSION}

Tai Chi is rooted in the traditional Chinese Taoist philosophy, and it is well known for its slow and graceful movements. ${ }^{43}$ Tai Chi exercises have been practiced for centuries in China for health promotion due to its inter-relatedness of mind, body and spirit, as well as the belief that human existence should be in harmony with nature at all times. ${ }^{44}$ In recent years, it has been gradually gaining popularity in Western societies. Research has shown that Tai Chi might be helpful for health-related fitness, by reducing blood pressure, controlling blood lipids and decreasing blood glucose, ${ }^{45} 46$ as well as improving balance control, ${ }^{47}$ cardiopulmonary function, ${ }^{48}$ quality of sleep and quality of life. ${ }^{49}$ However, most of the recent systematic reviews' results have suggested that larger scale studies with more participants and longer observation periods are necessary to further confirm and illuminate the effectiveness of Tai Chi. ${ }^{50} 51$

This is a randomised, parallel, controlled trial to evaluate the effectiveness of Tai Chi on reducing ischaemic stroke risk in people in the elderly community who have risk factors for ischaemic stroke. Its strengths include its rigorous design (RCT), target population (elderly community at high risk of ischaemic stroke) and emphasis on the protective effects of Tai Chi against ischaemic stroke risk. This paper describes the design, intervention development, baseline participants' demographics, study flow of the trial and baseline comparison, of primary and secondary outcomes between the Tai Chi and control groups. The baseline results suggested that no significant differences were found in demographics or primary and secondary outcomes when these comparisons were made, and a randomised, parallel, controlled design could provide good balance between the two groups. The results provided by the study will constitute good evidence for the protective effect of Tai Chi 
Table 4 Baseline comparison of secondary outcomes between Tai Chi and usual physical activities group

\begin{tabular}{|c|c|c|c|c|c|c|}
\hline \multirow[b]{2}{*}{ Variables } & \multicolumn{2}{|c|}{ Tai Chi group } & \multicolumn{2}{|c|}{$\begin{array}{l}\text { Usual physical activity } \\
\text { group }\end{array}$} & \multirow[b]{2}{*}{$\begin{array}{l}T(Z) \\
\text { value }\end{array}$} & \multirow[b]{2}{*}{ p Value } \\
\hline & $\mathbf{n}$ & $\begin{array}{l}\text { Mean } \pm \text { SD } \\
\text { (median, 75-25\%) }\end{array}$ & $\mathbf{n}$ & $\begin{array}{l}\text { Mean } \pm \text { SD } \\
\text { (median, 75-25\%) }\end{array}$ & & \\
\hline \multicolumn{7}{|l|}{ Cardiac structure and function } \\
\hline $\mathrm{AOD}, \mathrm{cm}$ & 85 & $2.73 \pm 0.32$ & 85 & $2.77 \pm 0.34$ & -0.748 & 0.456 \\
\hline $\mathrm{LAD}, \mathrm{cm}$ & 85 & $3.17 \pm 0.46$ & 85 & $3.18 \pm 0.52$ & -0.158 & 0.874 \\
\hline IVST, cm & 85 & $1.03 \pm 0.14$ & 85 & $1.02 \pm 0.15$ & 0.477 & 0.634 \\
\hline LVDD, cm & 85 & $4.38 \pm 0.51$ & 85 & $4.38 \pm 0.40$ & 0.050 & 0.960 \\
\hline LVPWT, cm & 85 & $0.94 \pm 0.11$ & 85 & $0.93 \pm 0.11$ & 0.707 & 0.480 \\
\hline LVAWT, cm & 85 & $1.03 \pm 0.12$ & 85 & $1.03 \pm 0.13$ & -0.176 & 0.861 \\
\hline $\mathrm{RAD}, \mathrm{cm}$ & 85 & 3.14 (3.34-2.95) & 85 & 3.06 (3.32-2.85) & -1.052 & 0.293 \\
\hline RVID, cm & 85 & $2.96 \pm 0.35$ & 85 & $2.97 \pm 0.35$ & -0.307 & 0.759 \\
\hline MPAD, cm & 85 & $2.05 \pm 0.20$ & 85 & $2.09 \pm 0.27$ & -1.106 & 0.270 \\
\hline LVEF, \% & 85 & $62.0(65.5-58.5)$ & 85 & $63.0(65.0-60.0)$ & -0.866 & 0.387 \\
\hline \multicolumn{7}{|l|}{ Static lung function } \\
\hline $\mathrm{VC}_{\max }, \mathrm{L}$ & 83 & $2.97 \pm 0.69$ & 82 & $2.86 \pm 0.70$ & 1.074 & 0.285 \\
\hline FEV1, L & 83 & $2.40 \pm 0.55$ & 82 & $2.31 \pm 0.59$ & 1.018 & 0.310 \\
\hline FEV1\%FVC & 83 & $88.18(91.65-83.50)$ & 82 & 87.51 (92.39-83.69) & -0.018 & 0.986 \\
\hline MVV, L/min & 83 & $78.96(100.34-66.74)$ & 82 & $86.03(107.0-72.2)$ & -1.142 & 0.253 \\
\hline Missing & 2 & & 3 & & & \\
\hline \multicolumn{7}{|l|}{ Plasma risk factor indexes } \\
\hline $\mathrm{TC}, \mathrm{mmol} / \mathrm{L}$ & 85 & $5.58 \pm 1.05$ & 85 & $5.52 \pm 1.17$ & 0.357 & 0.772 \\
\hline $\mathrm{TG}, \mathrm{mmol} / \mathrm{L}$ & 85 & $1.30(1.73-0.95)$ & 85 & $1.23(1.65-0.98)$ & -0.168 & 0.866 \\
\hline LDL, mmol/L & 85 & $3.62 \pm 0.90$ & 85 & $3.76 \pm 1.09$ & -0.931 & 0.353 \\
\hline $\mathrm{HDL}, \mathrm{mmol} / \mathrm{L}$ & 85 & $1.34(1.62-1.15)$ & 85 & $1.27(1.51-1.08)$ & -1.298 & 0.194 \\
\hline $\mathrm{FBG}, \mathrm{mmol} / \mathrm{L}$ & 85 & $5.41(5.82-5.06)$ & 85 & 5.37 (6.06-5.09) & -0.323 & 0.747 \\
\hline $\mathrm{HCY}, \mu \mathrm{mol} / \mathrm{L}$ & 85 & $10.80(12.80-8.42)$ & 85 & $9.82(12.70-8.25)$ & -1.085 & 0.278 \\
\hline \multicolumn{7}{|l|}{ Balance capability } \\
\hline Opened eyes perimeter, $\mathrm{mm}$ & 85 & 278.0 (347.0-233.5) & 85 & $267.0(322.5-213.5)$ & -1.220 & 0.222 \\
\hline Closed eyes perimeter, $\mathrm{mm}$ & 85 & $480.0(594.0-359.0)$ & 85 & $418.0(563.0-346.5)$ & -1.577 & 0.115 \\
\hline Opened eyes ellipse area, $\mathrm{mm}^{2}$ & 85 & $228.0(324.5-167.0)$ & 85 & $241.0(362.0-160.0)$ & -0.249 & 0.803 \\
\hline Closed eyes ellipse area, $\mathrm{mm}^{2}$ & 85 & $494.0(768.0-344.0)$ & 85 & $533.0(722.0-354.0)$ & -0.185 & 0.853 \\
\hline \multicolumn{7}{|l|}{ Proprioception capability } \\
\hline ATE of right lower limb & 85 & $39.0(58.5-31.5)$ & 85 & $39.0(58.5-31.5)$ & -0.708 & 0.479 \\
\hline ATE of left lower limb & 85 & $36.0(49.0-28.5)$ & 85 & $39.0(56.0-27.5)$ & -0.874 & 0.382 \\
\hline ATE of waist clockwise & 85 & $48.0(79.0-34.5)$ & 85 & $53.0(68.0-37.0)$ & -0.031 & 0.975 \\
\hline ATE of waist anticlockwise & 85 & $46.0(63.5-33.5)$ & 85 & $45.0(60.5-35.0)$ & -0.067 & 0.947 \\
\hline \multicolumn{7}{|l|}{ Physical parameters } \\
\hline $\mathrm{BMI}, \mathrm{kg} / \mathrm{m}^{2}$ & 85 & $25.37 \pm 3.19$ & 85 & $25.04 \pm 3.05$ & 0.686 & 0.494 \\
\hline WHR & 85 & $0.90 \pm 0.07$ & 85 & $0.90 \pm 0.07$ & 0.351 & 0.726 \\
\hline Flexibility, cm & 85 & $-2.67 \pm 11.32$ & 85 & $-3.60 \pm 12.37$ & 0.513 & 0.609 \\
\hline \multicolumn{7}{|l|}{ Psychological outcomes } \\
\hline SF-36 scales & & & & & & \\
\hline SF-36 (PCS) & 85 & $81.00(87.88-66.75)$ & 85 & $72.50(83.25-56.50)$ & -2.763 & 0.006 \\
\hline SF-36(MCS) & 85 & 85.25 (92.00-72.96) & 85 & $81.75(90.75-65.52)$ & -1.694 & 0.090 \\
\hline Quality of sleep (PSQI) & 85 & $6.0(9.0-4.0)$ & 85 & $6.0(9.0-4.0)$ & -0.642 & 0.521 \\
\hline Mood, (POMS-SF) & 85 & $93.0(106.0-82.0)$ & 85 & $94.0(115.0-80.5)$ & -0.165 & 0.869 \\
\hline
\end{tabular}

AOD, aortic diameter; ATE, average track error; BMI, body mass index; FBG, fasting blood glucose; FEV1, forced expiratory volume in $1 \mathrm{~s}$; FVC, forced vital capacity; HCY, homocysteine; HDL, high-density lipoprotein; IVST, interventricular septum thickness; LAD, left atrial diameter; LDL, low-density lipoprotein; LVAWT, left ventricular anterior wall thickness; LVDD, left ventricular diastolic diameter; LVEF, left ventricular ejection fraction; LVPWT, left ventricular posterior wall thickness; MCS, mental component summary score; MPAD, main pulmonary artery diameter; MVV, maximal voluntary ventilation; PCS, physical component summary score; POMS-SF, Profile of Mood States Short Form; PSQI, Pittsburgh Sleep Quality Index; RAD, right atrial diameter; RVID, right ventricle internal diameter; TC, total cholesterol; TG, triglyceride; $\mathrm{VC}_{\max }$, maximum vital capacity; WHR, waist-to-hip ratio.

against ischaemic stroke in the elderly community at high risk for ischaemic stroke.

A limitation of the study is the primary outcome measurement. Theoretically, the incidence of ischaemic stroke in the target population is the optimal measurement of the protective effects of Tai Chi on ischaemic stroke risk. If so, this trial will require a much longer observation period, even several years, and a much 
larger sample size. However, due to limitations of study funding, we have selected cerebral haemodynamic parameters to assess the possible risk of ischaemic stroke. Although studies have indicated that cerebral haemodynamic parameters were associated with vascular inflammation and atherothrombotic infarction and were strong independent predictive factors, ${ }^{52-54}$ they are still indirect and non-clinical end points for judging the effectiveness of Tai Chi for ischaemic stroke risk. In addition, because the transtemporal window is easily closed in elderly adults, especially older women, it usually causes poor ultrasonic transmission signals with much missing data, which can lead to some selection bias in evaluating cerebrovascular function. Another limitation of the protocol is that the participants screened might not be representative of the typical population. Because almost all of the participants come from the same community, living in an area close to the hospital, they might possibly have some differences from the target population. In addition, in the inclusion criteria, we defined 55-70 years of age as being elderly based on the current retirement age in China, which includes ages younger than the chronological age of over 60 years, which is accepted in many developed countries as a definition of elderly.

In summary, this trial demonstrates the necessity of preventing stroke in the older community population with a high risk of ischaemic stroke and the feasibility, utility and convenience of practicing Tai Chi. This study has the potential to provide information on the benefits of Tai Chi training to prevent ischaemic stroke risk in the elderly community population with risk factors for ischaemic stroke. If the intervention proves to be effective, the evidence-based findings will be available to the elderly community population with risk factors for ischaemic stroke. Further, we believe that these findings might also be suitable for other elderly people.

\author{
Author affiliations \\ ${ }^{1}$ College of Rehabilitation Medicine, Fujian University of Traditional Chinese \\ Medicine, Fuzhou, Fujian, China \\ ${ }^{2}$ Department of Physical Education, Fujian University of Traditional Chinese \\ Medicine, Fuzhou, Fujian, China \\ ${ }^{3}$ Fujian University of Traditional Chinese Medicine, Fuzhou, Fujian, China
}

Acknowledgements The authors thank the participants and staff in the communities and hospitals for their work in this project, including: Fujian University of Traditional Chinese Medicine Subsidiary Rehabilitation Hospital and Health Check Center of The Second People's Hospital of Fujian Province, and also thank American Journal Experts (AJE) for proper English language revision of the manuscript.

Contributors LC, GZ and JH conceived and designed the study, and contributed to drafting the manuscript. GZ and $X Z$ wrote the manuscript. TD, $\mathrm{DQ}$ and $\mathrm{KL}$ will take charge of Tai Chi exercise training. All the authors contributed to drafting the manuscript, and have read and approved the final version of the manuscript.

Funding The study was funded by the Collaborative Innovation Center for Rehabilitation Technology, Fujian University of Traditional Chinese Medicine (grant number X2012002-Cooperation) and the Social Development Guidance
Project of Fujian Province (2014Y003). These funding sources had no involvement with the conducting of the research or preparation of the manuscript. This trial is registered with http://www.chictr.org/cn ChiCTR-TRC-13003601.

Competing interests None declared.

Patient consent Obtained.

Ethics approval Medical Ethics Committee of The Affiliated People's Hospital of Fujian University of Traditional Chinese Medicine (Number 2013-020-02).

Provenance and peer review Not commissioned; externally peer reviewed.

Data sharing statement The original database will be available to all interested researchers on request by contacting the Ethics Board of FJTCM: kyc@fjtcm.edu.cn.

Open Access This is an Open Access article distributed in accordance with the Creative Commons Attribution Non Commercial (CC BY-NC 4.0) license, which permits others to distribute, remix, adapt, build upon this work noncommercially, and license their derivative works on different terms, provided the original work is properly cited and the use is non-commercial. See: http:// creativecommons.org/licenses/by-nc/4.0/

\section{REFERENCES}

1. Donnan GA, Fisher M, Macleod M, et al. Stroke. Lancet 2008;371:1612-23.

2. Murray CJ, Vos T, Lozano R, et al. Disability-adjusted life years (DALYs) for 291 diseases and injuries in 21 regions, 1990-2010: a systematic analysis for the Global Burden of Disease Study 2010. Lancet 2012;380:2197-223.

3. Saurabh R, Shrivastava PS, Shrivastava JD. Reduction in global burden of stroke in underserved areas. J Neurosci Rural Pract 2013;4:475-6.

4. Feigin VL, Lawes CM, Bennett DA, et al. Worldwide stroke incidence and early case fatality reported in 56 population-based studies: a systematic review. Lancet Neurol 2009;8:355-69.

5. Go AS, Mozaffarian D, Roger VL, et al. Heart disease and stroke statistics - 2014 update: a report from the American Heart Association. Circulation 2014;129:e28-292.

6. Kunst AE, Amiri M, Janssen F. The decline in stroke mortality: exploration of future trends in 7 Western European countries. Stroke 2011;42:2126-30.

7. Freiberg JJ, Tybjaerg-Hansen A, Jensen JS, et al. Nonfasting triglycerides and risk of ischemic stroke in the general population. JAMA 2008;300:2142-52.

8. Zhang $\mathrm{X}$, Patel $\mathrm{A}$, Horibe $\mathrm{H}$, et al. Cholesterol, coronary heart disease, and stroke in the Asia Pacific region. Int $J$ Epidemiol 2003;32:563-72.

9. Ovbiagele B, Nguyen-Huynh MN. Stroke epidemiology: advancing our understanding of disease mechanism and therapy. Neurotherapeutics 2011;8:319-29.

10. O'Donnell MJ, Xavier D, Liu L, et al. Risk factors for ischaemic and intracerebral haemorrhagic stroke in 22 countries (the INTERSTROKE study): a case-control study. Lancet 2010;376:112-23.

11. Law M, Wald N, Morris J. Lowering blood pressure to prevent myocardial infarction and stroke: a new preventive strategy. Health Technol Assess 2003;7:1-94.

12. Amarenco $P$, Labreuche J, Lavallée $P$, et al. Statins in stroke prevention and carotid atherosclerosis: systematic review and up-to-date meta-analysis. Stroke 2004;35:2902-9.

13. Blair SN, Goodyear NN, Gibbons LW, et al. Physical fitness and incidence of hypertension in healthy normotensive men and women. JAMA 1984;252:487-90.

14. Gallanagh S, Quinn TJ, Alexander J, et al. Physical activity in the prevention and treatment of stroke. ISRN Neurol 2011;2011:953818.

15. Goldstein LB, Adams R, Alberts MJ, et al. American Heart Association; American Stroke Association Stroke Council. Primary prevention of ischemic stroke: a guideline from the American Heart Association/American Stroke Association Stroke Council: cosponsored by the Atherosclerotic Peripheral Vascular Disease Interdisciplinary Working Group; Cardiovascular Nursing Council; Clinical Cardiology Council; Nutrition, Physical Activity, and Metabolism Council; and the Quality of Care and Outcomes Research Interdisciplinary Working Group. Circulation 2006;113: e873-923. 
16. Sacco RL, Gan R, Boden-Albala B, et al. Leisure-time physical activity and ischemic stroke risk: the Northern Manhattan Stroke Study. Stroke 1998;29:380-7.

17. Goldstein LB, Bushnell CD, Adams RJ, et al. Guidelines for the primary prevention of stroke: a guideline for healthcare professionals from the American Heart Association/American stroke association. Stroke 2011;42:517-84.

18. Liu JY. The effect of Tai Chi Chuan on body-mind. Tamkang 1975;13:217-23.

19. Wayne PM, Kaptchuk TJ. Challenges inherent to t'ai chi research part I-t'ai chi as a complex multicomponent intervention. J Altern Complement Med 2008;14:95-102.

20. Maciaszek J, Osinski W. The effect of Tai Chi on body balance in elderly people-a review of studies from the early 21 st century. Am J Chin Med 2010;38:219-29.

21. Wang F, Lee EK, Wu T, et al. The effects of tai chi on depression, anxiety, and psychological well-being: a systematic review and meta-analysis. Int J Behav Med 2014;21:605-17.

22. Schleicher MM, Wedam L, Wu G. Review of Tai Chi as an effective exercise on falls prevention in elderly. Res Sport Med 2012;20:37-58.

23. Tsai JC, Wang WH, Chan $\mathrm{P}$, et al. The beneficial effects of Tai Chi Chuan on blood pressure and lipid profile and anxiety status in a randomized controlled trial. J Altern Complement Med 2003;9:747-54.

24. Lee MS, Jun JH, Lim HJ, et al. A systematic review and meta-analysis of Tai Chi for treating type 2 diabetes. Maturitas 2015;80:14-23

25. Thomas GN, Hong AW, Tomlinson B, et al. Effects of Tai Chi and resistance training on cardiovascular risk factors in elderly Chinese subjects: a 12-month longitudinal, randomized, controlled intervention study. Clin Endocrinol (Oxf) 2005;63:663-9.

26. Lee EN. The effects of Tai Chi exercise program on blood pressure, total cholesterol and cortisol level in patients with essential hypertension. Taehan Kanho Hakhoe Chi 2004;34:829-37.

27. Fong SS, Ng SS, Luk WS, et al. Effect of a 6-month Tai Chi qigong program on arterial hemodynamics and functional aerobic capacity in survivors of nasopharyngeal cancer. J Cancer Surviv 2014;8:618-26.

28. Lu X, Hui-Chan CW, Tsang WW. Tai Chi, arterial compliance, and muscle strength in older adults. Eur J Prev Cardiol 2013;20:613-19.

29. Calil I, Tineli RA, Vicente WV, et al. The concept of crosstalk and its implications for cardiovascular function and disease. Arq Bras Cardiol 2007;88:e26-31.

30. Dong J, Inthavong K, Tu J. Image-based computational hemodynamics evaluation of atherosclerotic carotid bifurcation models. Comput Biol Med 2013;43:1353-62.

31. Hartley L, Flowers N, Lee MS, et al. Tai chi for primary prevention of cardiovascular disease. Cochrane Database Syst Rev 2014;4: CD010366.

32. Sheng JZ, Gu LX, Fu ZW, et al. The comprehensive book of Tai Ji Quan. 2nd edn. Beijing, China: People Sports Press, 2006.

33. Li L, Wang H, Shen Y. Development and psychometric tests of a Chinese version of the SF-36 Health Survey Scales. Zhonghua $Y u$ Fang Yi Xue Za Zhi 2002;36:109-13.

34. Ware JE Jr, Sherbourne CD. The MOS 36-item short-form health survey (SF-36). I. Conceptual framework and item selection. Med Care 1992;30:473-83.
35. Jin WZ, Yu HT. A study of the reliability and validity of SF-36 scale on evaluating health of population. Chinese Health Resources 2012;15:265-7.

36. Backhaus J, Junghanns K, Broocks A, et al. Test-retest reliability and validity of the Pittsburgh Sleep Quality Index in primary insomnia. J Psychosom Res 2002;53:737-40.

37. Buysse DJ, Reynolds CF, Monk TH, et al. The Pittsburgh sleep quality index: a new instrument for psychiatric practice and research. Psychiatry Res 1989;28:193-213.

38. Carpenter JS, Andrykowski MA. Psychometric evaluation of the Pittsburgh Sleep Quality Index. J Psychosom Res 1998; 45:5-13.

39. Liu XC, Tang MQ, Hu L, et al. Reliability and validity of Pittsburgh Sleep Quality Index. Chinese J Psychiatry 1996;(02):103-7.

40. Chen KM, Snyder M, Krichbaum K. Translation and equivalence: the Profile of Mood States Short Form in English and Chinese. Int $J$ Nurs Stud 2002;39:619-24.

41. Song C, Wen JL. The preliminary revision of Brief Profile of Mood State (BPOMS). Chinese Mental Health J 2003;17:768-70.

42. Zhang LY, Bai WQ. Relationship between age and Cerebral blood flow velocity with pulse index. Chinese $J$ Convalescent Med 2010;19:166-7.

43. Koh TC. Tai Chi Chuan. Am J Chin Med 1981;9:15-22.

44. Lan C, Wolf SL, Tsang WW. Tai chi exercise in medicine and health promotion. Evid Based Complement Alternat Med 2013;2013:298768

45. Chang MY, Yeh SC, Chu MC, et al. Associations between Tai Chi Chung program, anxiety, and cardiovascular risk factors. $A m \mathrm{~J}$ Health Promot 2013;28:16-22.

46. Xiong $\mathrm{KY}, \mathrm{He} \mathrm{H}, \mathrm{Ni} \mathrm{GX}$. Effect of skill level on cardiorespiratory and metabolic responses during Tai Chi training. Eur J Sport Sci 2013;13:386-91.

47. Chung PH, Lin GL, Liu C, et al. The effects of Tai Chi Chuan combined with vibration training on balance control and lowe extremity muscle power. J Sports Sci Med 2013;12:19-26.

48. Niu R, He R, Luo BL, et al. The effect of tai chi on chronic obstructive pulmonary disease: a pilot randomised study of lung function, exercise capacity and diaphragm strength. Heart Lung Circ 2014;23:347-52.

49. Lo CM, Lee PH. Feasibility and effects of TAI CHI for the promotion of sleep quality and quality of life: a single-group study in a sample of older Chinese individuals in Hong Kong. J Gerontol Nurs 2014;40:46-52.

50. Lin CL, Lin CP, Lien SY. The effect of tai chi for blood pressure, blood sugar, blood lipid control for patients with chronic diseases: a systematic review. Hu Li Za Zhi 2013;60:69-77.

51. Blake $\mathrm{H}$, Hawley $\mathrm{H}$. Effects of Tai Chi exercise on physical and psychological health of older people. Curr Aging Sci 2012; 5:19-27.

52. Ridger V, Krams R, Carpi A, et al. Hemodynamic parameters regulating vascular inflammation and atherosclerosis: a brief update. Biomed Pharmacother 2008;62:536-40.

53. Nishiyama $Y$, Katsumata $T$, Otori $T$, et al. Carotid hemodynamic parameters are useful for discriminating between atherothrombotic infarction and lacunar infarction. J Stroke Cerebrovasc Dis 2010;19:441-9.

54. Guo JP, Huang JY, Guan YT, et al. A cohort study on the relationship between cerebrovascular hemodynamic changing and risk of stroke. Zhonghua Yu Fang Yi Xue Za Zhi 2013;47:323-7. 